\title{
Exploring Value Variations in Instructor Presence Techniques for Online Students
}

\author{
Sarah N. Robertson, PhD \\ Faculty, College of Humanities and Social Sciences \\ Grand Canyon University \\ John P. Steele, MEd, MPsy \\ Assistant Professor, College of Humanities and Social Sciences \\ Grand Canyon University \\ B. Jean Mandernach, PhD \\ Leadership, Center for Innovation Research and Teaching \\ Grand Canyon University
}

\begin{abstract}
This study sought to define and measure online undergraduate students' perceived value of instructor presence techniques across five communication mediums per pedagogical goal (connection to course content, connection to classmates, connection to the instructor, foster interest, and facilitate immediate feedback). Students found personalized written messages from an instructor $(M=4.61)$ as most valuable due to their ability to provide immediate feedback. Interactive phone calls $(\mathrm{M}=3.24)$ were the least valuable in the area of familiarity. Results indicate all instructor presence techniques had value, but some were more valuable than others.
\end{abstract}

As more universities provide fully online programs, it is imperative to develop techniques that continue to improve learning and teaching online. To illustrate, at least $32 \%$ of college students enrolled in an online course in 2013 (Sun \& Chen, 2016). More than six million students had completed at least one online course by 2017 (Pawl, 2018). Plus, more than 279 colleges and universities provided fully online courses in 2019 (U.S. Department of Education, Recognition and Accreditation, 2019).

With continued enrollment growth in online-only programs, it is critical that educators continue to adapt and meet the needs of their students in online settings. Meeting online students' needs can be done with the use of learning objectives and the Community of Inquiry (COI) model as guides to help educators select tools that will help students make the best connections with their content, classmates, and teacher (Thompson et al., 2017). The CoI model is a pedagogical theory that integrates social, teaching, and cognitive presences. The utilization of the CoI model has been theorized to most closely create an ideal educational experience. Within the CoI model, social presence consists of the ability of all the participants in the community to project themselves socially and emotionally within the classroom environment (community of inquiry) (Garrison et al., 2000). Teaching presence is the shared responsibility for the educational experience among students and teachers (Garrison et al., 2000). Cognitive presence consists of "...the extent to which learners are able to construct and confirm 
meaning through sustained reflection and discourse in a critical community of inquiry" (Garrison et al., 2000, p. 90). Each of these presences overlaps with one another. See Figure 1 below for a graphic of the standard CoI model.

\section{Figure 1}

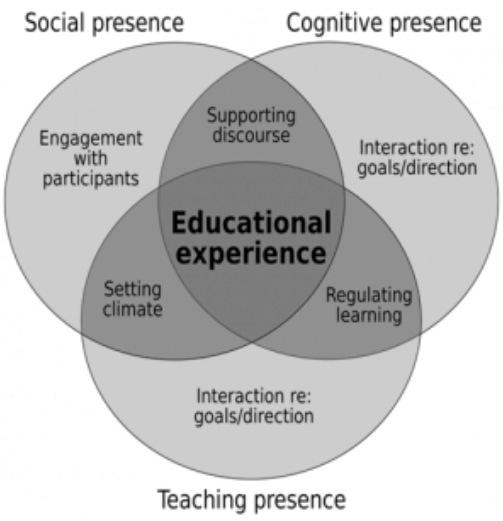

Note. CoI Framework. Elements of an educational experience (Garrison, Anderson, \& Archer, 2010).

\section{Instructor Presence within CoI}

As more and more institutions adopt this framework for use in curriculum design, course development, and instructor training, additional dialogue and research have been completed using the model as a theoretical foundation. "Although thousands of CoI-based articles have been published (Befus, 2016), those critical of the framework suggest that more presences should be added in the framework" (Bektashi, 2018, para. 1). Instructor presence is one such presence that needs identification within

\section{Figure 2}

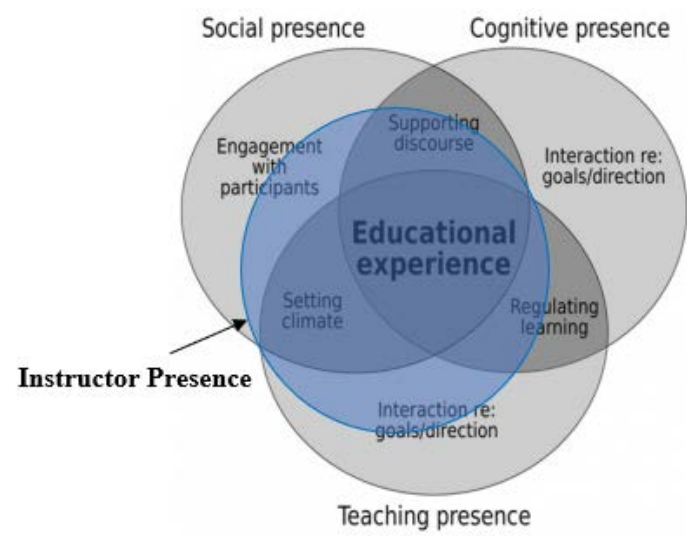

Note. Visual of proposed instructor presence within CoI Framework. the CoI framework. This presence is purported to overlap social and teaching presences (Richardson et al., 2015). See Figure 2 for a visual of where instructor presence would be within the CoI model. Instructor presence is difficult to describe, as it is not a physical presence in an online classroom but rather the essence of the instructor's presence while a learner is in class. Some of the previous literature describes this concept as instructor social presence (Collins et al., 2019). The purpose of this conceptual framework behind the 
terminology of instructor presence is designed to help researchers understand the role of online instructors. The latter may teach pre-designed courses, design their own courses, or are designer-instructors of the course (Collins et al., 2019). Instructor presence is the central area of focus within the research study.

In the traditional setting, instructor presence develops naturally while the instructor is in front of the classroom as students can physically see and hear the instructor (Kennette \& Redd, 2015). On the contrary, in the online setting, the instructor must work to develop this instructor presence. Fostering instructor presence has been of the utmost importance as it is predicted to have a positive impact on online undergraduate students who are often at the highest risk of dropping out. Student engagement and student connection with the instructor are relational (Collins et al., 2019). In a similar study, which investigated the role of interaction with dropping out of school, it was concluded that the learner-instructor interaction had the most considerable effect on the dropout rate (Croxton, 2014). Though all instructor presence techniques could help to increase instructor presence and increase learner-instructor interactions, some formats may have differential perceived value with different pedagogical goals. Thus, this study aims to examine the perceived value of various forms of instructor presence techniques for meeting specific goals (i.e., connecting to course content, connecting to classmates, connecting to the instructor, fostering level of interest, providing immediate feedback). Past studies have assessed specific techniques to increase teaching presence in the online classroom (Steele, Robertson, et al. 2017; Steele et al., 2018). However, instructors and researchers have yet to determine their value in comparison to one another and, if any, have equivalent perceived value to synchronous learning options such as live video conference calls.

One current understanding is that synchronous communication, such as phone calls and live video conferencing, is the best form of integrating instructor presence because it can break down the psychological and physical barriers that interrupt interaction and participation (Falloon, 2011). Synchronous communication can be challenging to achieve as completing learning tasks in an asynchronous environment is the primary design and management need for the online classroom. Clark and Mayer (2011) propose instead that incorporating an instructor's sense of presence into asynchronous learning components, such a pre-recorded video lectures and audio feedback on assignments, could enhance learning and make the learner feel more connected to the instructor and course. It could be that any method an instructor uses to integrate their sense of presence into an online classroom may be well received by learners, despite the specific course content, design, learning management system, or teaching style. After all, the purpose of items such as personalized lectures, announcements, and phone calls is to display the instructor's presence to help students feel more connected, comfortable taking learning risks, and ease in approaching the instructor with questions during a course (Collins et al., 2019).

Though an instructor may have helped to develop the course, including the syllabus, assignments, discussion questions, selected the ebook, and/or additional materials, it does not necessarily mean that the student will feel their instructor presence within the course (Bolldén, 2016). Collins et al. (2019) noted that building instructor presence is a vital element of an instructor's role and vitally important to the overall student learning experience. When instructors find a way to embody their 
presence in the classroom, students report a stronger connection to the instructor, class, and even sometimes content (Bolldén, 2016; Steele, Robertson, et al., 2017; Steele et al., 2018). An instructor's efforts to enhance their instructor presence within a classroom can result in greater connection with their students because of the connection that such presence can materialize for the learner.

Some activities that are theorized to add instructor presence within the classroom include creating a video biography, video welcome message, weekly checkin videos, instructor created podcasts, sharing personal examples with the class, instructor generated assignments, content, direction clarification posts, and more (Kupczynski et al., 2010; Steele, Robertson, et al., 2017; Steele et al., 2018). Furthermore, all of these methods of incorporating instructor presence into the classroom may have added benefits. For instance, some may also increase immediacy for the student, further connect students with class content, or others are an opportunity for students to gain elaborative feedback on an assignment. The enhanced value can end up crossing over into all three presences of CoI (teaching, social, and cognitive) (Kozan \& Caskurlu, 2018). For example, students may feel comfortable enough with the instructor to also project themselves as individuals in the classroom (Collins et al., 2019). Moreover, instructors can encourage deeper reflective thinking from their learners with the addition of their instructor presence within discussion materials. Many different communication mediums allow for instructors to increase their instructor presence.

\section{Communication Mediums}

With advancements in technology, humans have increased options for communication mediums. A medium is the method or channel one uses to communicate. In the recent past, these channels were often chunked into three larger communication medium umbrellas (traditional, email, and social media) (O'Neal et al., 2016). Online education presents an added layer as personal learning environments (PLEs) or learning management systems (LMS) use social software to enable instructorto-learner and peer-to-peer communication (Jeremić et al., 2012). Typically, instructor presence techniques are used within the LMS in one of four mediums: typed/written words, images, audio, and video. Outside of the LMS, instructors and students can also interact via typed/written words through email, text messages, and mailed letters. While each of these mediums offers an opportunity for instructors to build their presence, little is known about which format is best aligned for meeting various anagogical goals.

\section{Typed Words}

The traditional format of teaching content in the online modality originates with simple text (Jeremić, et al., 2012). Text-based instruction is the foundational approach in the online modality. The original study with the personalization principle simply changed the text in a quiz from a more formal third person to a friendlier sounding conversational tone displaying the power of personalization with text (Moreno \& Mayer, 2004). Furthermore, Moreno and Mayer (2004) found that 
personalizing text reduces the cognitive load allowing students to learn better. Personalizing text is perhaps the easiest way to increase instructor presence by changing the text to less formal tone and personalizing it with names and instructor names.

- $\quad$ Personalized Typed Words Example: Using the student and instructor names in feedback and/or conversational language.

- $\quad$ Non-Personalized Typed Words Example: A curriculum generated written lecture and/or formal language.

\section{Static Visual}

Verbal lectures and written text are not always enough to explain concepts or even the relation of one idea to another in a course offered in any modality. Static visuals such as diagrams, figures, charts, maps, images, and other graphics enhance the likelihood of student understanding (Shabiralyani et al., 2015). Besides, images can help aid in storing the information into memory, improve the learning environment, and promote thinking (Shabiralyani et al., 2015). Pao-Nan Chou and Hsi-Chi Hsiao (2010) found that during a lower-order thinking process, text-based instruction was inferior to static visual instruction. Additionally, instructors can personalize the classroom to increase instructor presence with visuals as including a picture of themselves in the classroom or class profile.

\section{Audio}

Audio content can add another supplemental way to enhance and deliver content in the online modality. Supplements such as audio lectures can be time savers for faculty due to the ease and speed of creating them (Copley, 2007). Not only can it be beneficial for faculty, but supplements such as audio lectures or podcasts can also offer students mobility to listen to them on the move (Steele, Robertson, et al., 2017; Steele et al., 2018). Audio files also provide a great deal of flexibility to easier accessibility with regards to bandwidth (Steele, Nordin, et al., 2017). An example of personalized audio is a personalized MP3 audio grading feedback recorded by the classroom instructor. Audio can also be provided that aids in instruction but was not personalized by the instructor.

\section{Video}

Personalized videos are one of the easiest ways online instructors can boost their instructor presence and connection with the class. [author redacted] et al. found that students who viewed video lectures with their instructors in the videos were more likely to have an increased connection to their instructor. Also, the students in the study indicated that personalized videos with their instructor made them feel more connected to the classroom (Steele, Robertson, et al., 2017; Steele et al., 2018). Mayer et al. (2004) determined that eliminating unnecessary words, sounds, and/or pictures reduced the cognitive load while increasing learning. Thus, the shorter and more to the point, the more effective the video will be. Nagy (2018) found that the attitude toward 
and the perception of the usefulness of the videos to be the most critical factors that influenced video usage. Non-personalized videos can also be helpful but did not rank as high in helping students feel connected with their classroom and instructor. An example of a non-personalized video lecture is an educational YouTube video created by someone other than the instructor.

\section{Research Question}

\section{Study Design and Procedure}

What instructor presence techniques are rated as most and least valuable based on need: Connection to course content, connection to classmates, connection to the instructor, increases in the level of interest, provides an outlet for immediate feedback, and medium: text, image, video, and audio.

\section{Survey Creation}

The researchers created a list of instructor-generated materials that have been established to increase instructor presence in the online classroom (Steele, Robertson, et al., 2017; Steele et al., 2018) across the four proposed communication mediums (written words/text, images, audio, and video) that an instructor might use to enhance their instructor presence within an online classroom. See Appendix A for a matrix example.

Upon completing the matrix, each box was then transformed into a survey question. The questions are designed as five-point agree/disagree Likert scale statements. The survey scale ranged from 1-5 with 1 indicating no value, 3 indicating the neutral value, and 5 indicating the highest value. To reduce the likelihood of survey fatigue, the survey was divided into four parts. Part one included informed consent, demographic questions, and all questions assessing value differences of instructor presence techniques within the medium of images/visuals. Parts two through four included all items assessing value differences of teaching presence within each of the remaining mediums (typed/written words, audio, video, and interactive web). After creating the initial personalization matrix, the researchers deleted instances of replication between one part of the study and another. These elements were removed because the type of value did not apply to that particular communication medium and instructional example. For example, interactive video is not able to or likely to be printed out by a student. These sections of the matrix were eliminated. All four parts of the survey were integrated into the web 2.0 Survey Monkey tool. Each piece of the survey took students approximately 5-15 minutes to complete.

\section{Procedure}

After research questions and survey creation, site and IRB approval were completed. A link to access the survey within Survey Monkey was created and included informed consent with a click to confirm button at the end before participant access to demographic and part 1-4 survey questions. Two instructors volunteered to 
post a recruitment script to participants within designated courses. Data collection spanned from January 2018 to June 2018.

\section{Population and Sample Size}

The target population for the study was full-time, undergraduate online students enrolled in one of two of their first year, 100-level courses. These courses at the university are seven weeks long. Each course has approximately 25 students enrolled. Nearly 6,300 students enrolled in either of the two designated courses during the duration of the study. Two of the instructors scheduled to teach the courses volunteered to post a recruitment script with a survey link to participants using an announcement within the first five weeks of each of their classes. For this study, 18 consecutive course sections were used per instructor resulting in a sample of 900 students. The four-part survey was quite long. Participants were provided the option to end the survey at the end of each survey part. The ability to exit the survey was provided to help prevent survey fatigue. That said, not all participants completed all parts of the survey. Only 111 participants and their responses could be utilized during data analysis. Ages for the 111 participants ranged from 18-64. The mean age was 32.26. The mode was 22, 23, and 31 years old at 7 participants each.

\section{Results}

Means were obtained for all items and subscales in the survey. The means for each were placed into the matrix to compare values (Appendix C). Sections of the table with an $X$ represent instances where the researchers did not ask a question to measure that particular value and communication medium because it was either not applicable or was already assessed in some other way in the matrix. Highlighted means indicate the highest mean for each instructor presence technique (Appendix A).

All instructor presence techniques had at least one dimension of value with a mean $\geq 3.55$, and no techniques had values with means below 3.24, as noted in the Table 2. Means support that students do find some level of value in all instructor presence techniques. Surprisingly, the highest mean across all mediums and perceived values were that of typed/written words only (such as personal responses from the instructor within the individual forum) with a value provides immediate feedback $M=4.61$. While this was not what was expected, it did confirm students highly value typed/written words that are instructor-generated. In fact, typed/written word techniques including typed/written directions $\mathrm{M}=4.59$ and additional posts in class (such as instructor added communication and checks for understanding) $\mathrm{M}=4.54$, had the second and third highest means; student comments highlighted the value of typed/written words was linked to the ability to access at any time. The fourth highest mean of $M=4.41$ was documented for static image with the student value description of "...helps make course content more interesting," (Table 1). Though techniques using video scored with a high value mean $M=4.40$, value means were often below that of static image, and typed/written word value means. The lowest rated value mean across all modes and values was 3.24 interactive audio phone calls with a mean of 3.24 because "...it aligns with how I am used to learning," as noted in Table 2. Students in this study preferred 
asynchronous techniques to that of synchronous techniques. It is important to note, particularly in relation to the preference for asynchronous communication, that the current study collected data prior to the 2020 pandemic. While synchronous videoconferencing became popular during emergency remote teaching that occurred during the pandemic, typical online learning utilizes very limited synchronous interaction.

\section{Discussion and Implications}

The results confirmed that students found value in all dimensions. Surprisingly, the text dimension received the highest score of 4.61 . While this was not what had been expected, it did confirm the value that students found in personalized text. The results affirmed that students deem the highest value in instructor personalized text. This result is good news for instructors, and a reminder to all that though we may continue to integrate video, images, and audio into online classrooms, our written messages to students are still very valuable. Next, the second highest was Static (Image) category with a 4.41. The great part about this is that these are two (text and static images) of the more common ways that instructors will personalize content with instructor presence techniques.

Additionally, results confirmed that students found some value in all of the different dimensions of personalization with instructor presence techniques. The biggest revelation is that students rated personalized typed messages as the best value. Thus, the Moreno and Mayer (2002) study into the element of the personalization principle where the researchers changed the text on a quiz from a more formal tone to an informal conversational tone caused students to score higher on a quiz. Simply personalizing the text ...though we may continue to integrate video, images, and audio into online classrooms, our written messages to students are still very valuable.

and using an informal tone continues to be a great way to build instructor presence online. The good thing is that for a busy faculty member, this is sometimes the fastest and easiest way to build instructor presence.

Consequently, the second highest-rated value was the static image. However, this does not diminish that other forms of incorporating instructor presence into the classroom were also valuable in their own ways. Thus, adding some form of instructor presence to the online classroom is better than not including any at all. However, adding a bit of variety by using a few different instructor presence techniques may be the most beneficial way to meet the varying needs and desires of a wide range of students offering more convenience. The best part is that the two dimensions with the highest rated values (text and visuals) are also the easiest for busy instructors to incorporate. Therefore, the most effective and efficient ways that an instructor may be able to incorporate instructor presence are also the easiest and least time-consuming.

The results further reveal the complexity of online instruction. What was previously known is that instructor presence is in fact valued and important within online learning. Bolldén (2016) noted that instructors who embody their presence in the classroom results in stronger student connections to the instructor, class, and even sometimes content. Embodiment of the instructor, however, may be that it is not a one- 
size-fits all for instructors, classes and students alike. In this study, students preferred asynchronous techniques to that of synchronous techniques. There could be a few different explanations or implications from the data. First, students have different preferences for the ways they would prefer to receive content. From a teaching perspective, the results reinforce the importance of providing a variety of ways for students to access course information. For example, Steele et al. (2018) recommend providing choices for online students each week by giving a typed, video, and audio version of the weekly lecture. Within each course section, online learners can come from multiple states with environmental differences as well as have a varying schedule and job-related challenges. When the factors mentioned above are coupled with students' personal learning preferences, it is apparent why the provisions of options for receiving information personalized by the instructor are vital.

Next, instructors need to consider the element of convenience for the student. The data is clear as the pre-recorded video domain was rated as valuable with the highest mean value ( $M=4.40)$ because "...I have access to it when I need it," and typed, audio-recorded messages were also deemed as valuable for the same reason. Students preferred techniques that were convenient and accessible. So, in the asynchronous environment, instructors and designers must take into consideration whether the technique(s) that are incorporated will be convenient and accessible to all students. Also, many online students may find it hard to participate in synchronous activities due to limited technology capability, work schedules, and other family commitments, which contribute to why the students chose to attend school in the online modality (Evans et al., 2014).

Furthermore, while students seemed to prefer asynchronous techniques to that of synchronous techniques, some of their differences in value may also be due to how they are used to learning in the asynchronous classroom and how much exposure they have had to some of the techniques. A Falloon (2011) study found that phone calls and live video conferencing were a great way to break down the psychological and physical barriers that interrupt interaction and participation. However, the current research demonstrates that though the phone calls and live video conferencing are indeed valued, there are several more convenient asynchronous instructor presence techniques that can break down these barriers and increase instructor presence that students with limited time may instead gravitate to when offered. Additionally, incorporating fancy new technologies or video conferencing may be a great way to provide instructor presence to students, but also may limit the number of students who are able to engage with it. Thus, instructors must consider the population of students when incorporating or creating content. The sample in study was limited to online students. With this in mind, traditional students or students in a hybrid program may have different preferences.

It is also important to note that the school can only provide the virtual environment of the classroom. When considering this, though students may state they want/prefer something like a video lecture because "...the tool promotes a deeper understanding," restrictions in the student's physical environment may impact their likelihood of choosing to learn or connect with those resources. For example, a student may have time for class while driving to work in the mornings, but this then would negate the ability to read written text or watch a video. In another example, a student 
may only have time for class after kids are put to bed and prefer reading material to limit noise.

The examples as mentioned earlier introduce additional study implications for faculty and institutions. If instructors can provide students with multiple medium options to receive and engage in content it offers greater student accessibility. For example, if an instructor creates a lecture and provides it in all three mediums (video, audio, and text-based), the student has multiple ways to receive the content. Consequently, many instructors may not have time to create a resource through multiple mediums. Finding multiple mediums is where it can be prudent for instructors to select a tool that can allow the co-creation of a resource through multiple mediums. For example, the record feature on Zoom automatically creates both audioonly and video with audio files. That said, Zoom does not create a transcript, so the written version would either need to be scripted out beforehand or transcribed afterward either by the instructor or through a transcription service such as Rev.com. Any additional support that an institution can provide instructors to help make integrating their presence through multiple mediums is helpful.

While faculty have differences in their preferences in student-valued teaching presence tools, so too is there variance in school standards of practice, faculty expectations, and support resources for faculty between universities. It is the marriage of these factors that need to be considered. Instructors and institutions need to consider the audience, course, the tool being used, and the content when using various communication mediums to build instructor presence. Instructor presence levels in the online classroom can also be throttled or catalyzed by the learning management system (LMS) in regards to how easy it is to insert additional material and/or how involved the instructors are allowed to be in the process of content creation and delivery. Additional considerations are whether students can see that some aspects of classroom design, management, and grading are personalized by the instructor (Milman, 2016). These last points raise limitations for the present study.

\section{Limitations and Recommendations}

From a research standpoint, it is vital to consider circumstantial differences within a particular course or LMS designs. For example, text-only (personal responses from the instructor within the individual forum) was most valuable because "...it aligns with how I am used to learning." Data for the study was only pooled from a sample of students within two undergraduate courses within one private university in the Southwest. Other courses, degree programs, learning management systems, or even institutions may have small differences in the way they run and thus change how/what learners value.

The creation of the survey to measure students perceived value of varying instructor personalization techniques was also a component of the study. This was the first use of the survey. No standardized baseline for each mean value has been determined. Further research to establish a baseline and complete a factorial analysis of the tool would be helpful.

Furthermore, the study was created to be posted within a course in "parts" in an attempt to reduce survey fatigue. Though parts 1 and 2 had completion rates of 500+ 
participants, only 111 participants and their responses could be utilized after the matching of participant codes across all four parts of the survey and are noted as a limitation of the study. Though the survey was divided into parts in an attempt to reduce survey fatigue, it may have still occurred and may have been the cause for less participation in the later two parts of the survey. Survey fatigue may have been avoided with a shorter survey. Thus, future studies could focus on revising the tool into a more concise, one-time survey.

There is value in personalizing content for students through instructor presence techniques, but how breakdown the themes and determine the value can be explored further. Future research could delve deeper into the different themes listed below:

- Public interaction (Example: Whole class instruction) versus private interaction (Example: Individualized to one student). While it was clear that the students value instructor personalization, it was not clear if they valued private interaction or public interaction.

- Generic content (Example: Curriculum created video that is placed in each course) versus Instructor generated (Example: Instructor created YouTube video lecture). It may not have always been clear to students what was generic or instructor generated content. Again, there was no differentiation as to whether or not students valued one over the other.

- Teaching (Example: providing assignment direction clarifications, additional examples, or asking follow up questions to assess student learning) versus design (Example: Creation of assignments, determination of participation expectations, placement of other resources in the course).

The objective of the study was to pinpoint some of the most valuable areas in each dimension or most valuable dimensions where instructors can add their presence into the online classroom with instructor presence techniques to get the biggest benefit. The researchers ponder if some of the lower scores were because students did not realize that these instructor presence techniques are personalized by the instructor because they are based on a program outside of the classroom or whether students thought the institution designed them. It would be of interest to find out why students rated the synchronous techniques with the lowest values. Regardless, of the technique that is applied including any instructor presence techniques appear to add value to the online classroom.

\section{References}

Bektashi, L. (2018). Community of inquiry framework in online learning: Use of technology. Technology and the Curriculum.

https://techandcurriculum.pressbooks.com/chapter/coi-and-online-learning/

Bolldén, K. (2016). Teachers' embodied presence in online teaching practices. Studies in Continuing Education, 38, 1-15.

https://doi-org.lopes.idm.oclc.org/10.1080/0158037X.2014.988701 
Clark, R. C., \& Mayer, R. E. (2011). E-Learning and the science of instruction: Proven guidelines for consumers and designers of multimedia learning ( $3^{\text {rd }}$ ed.) John Wiley \& Sons.

Collins, K., Groff, S., Mathena, C., \& Kupczynski, L. (2019). Asynchronous video and the development of instructor social presence and student engagement. Turkish Online Journal of Distance Education, 20, 53-70.

Croxton, R. A. (2014). The role of interactivity in student satisfaction and persistence in online learning. Journal of Online Learning and Teaching, 10, 314- 325.

Evans, S., Knight, T., Sønderlund, A., \& Tooley, G. (2014). Facilitators' experience of delivering asynchronous and synchronous online interprofessional education. Medical Teacher, 36, 1051-1056.

https://doi-org.lopes.idm.oclc.org/10.3109/0142159X.2014.918254

Falloon, G. (2011). Making the connection: Moore's Theory of Transactional Distance and its relevance to the use of a virtual classroom in postgraduate online teacher education. Journal of Research on Technology in Education International Society For Technology in Education, 43, 187-209.

https://files.eric.ed.gov/fulltext/EJ918904.pdf

Garrison, D. R., Anderson, T., \& Archer, W. (2000). Critical inquiry in a text-based environment: Computer conferencing in higher education. The Internet and Higher Education, 2, 87-105.

https://cde.athabascau.ca/coi site/documents/Garrison Anderson Archer C ritical Inquiry model.pdf

Jeremić, Z., Milikić, N., Jovanović, J., Brković, M., \& Radulović, F. (2012). Using online presence to improve online collaborative learning. International Journal of Emerging Technologies in Learning, 7, 28-35.

https://doi.org/10.3991/ijet.v7iS1.1918

Kennette, L. N., \& Redd, B. R. (2015). Instructor presence helps bridge the gap between online and on-campus learning. College Quarterly, 18.

https://files.eric.ed.gov/fulltext/EJ1095942.pdf

Kozan, K., \& Caskurlu, S. (2018). On the Nth presence for the Community of Inquiry framework. Computers E Education, 122, 104-118.

http://dx.doi.org/10.1016/j.compedu.2018.03.010

Kupczynski, L., Ice, P., Wiesenmayer, R., \& McCluskey, F. (2010). Student perceptions of the relationship between indicators of teaching presence and success in online courses. Journal of Interactive Online Learning, 9, 23-43. https://www.ncolr.org/jiol/issues/pdf/9.1.2.pdf

Milman, N. B. (2016). Instructor roles in next generation digital learning environments. Distance Learning, 13, 67.

https://expert.gwu.edu/display/doc-34e8ad282fd5a0583fa3d099718b9a68

Moore, M. (1997). Theory of transactional distance. In D. Keegan (Ed.), Theoretical Principles of Distance Education (pp. 22-38). Routledge. http://www.c3l.unioldenburg.de/cde/found/moore93.pdf

Moreno, R. \& Mayer, R. E. (2004). Personalized messages that promote science learning in virtual environments. Journal of Educational Psychology, 96(1), 165-173. https://doi.org/10.1037/0022-0663.96.1.165 
Nagy, J. T. (2018). Evaluation of online video usage and learning satisfaction: An extension of the technology acceptance model. International Review of Research in Open and Distributed Learning, 19, 160-185.

https://doi.org/10.19173/irrodl.v19i1.2886

O'Neal, R. B., Green, M., Gergen, E., \& Yu Sun. (2016). Exploring the differences that communication medium has on perception of leadership style: Does communication medium affect the leadership rating of the leader? Business Management Dynamics, 6, 1-16.

http://bmdynamics.com/issue pdf/bmd110609-\%2001-16.pdf

Pao-Nan Chou, \& Hsi-Chi Hsiao. (2010). The effect of static visual instruction on students' online learning: A pilot study. Interdisciplinary Journal of Information, Knowledge, and Management 5, 073-081.

https://citeseerx.ist.psu.edu/viewdoc/download?doi=10.1.1.476.2272\&rep=re p1\&type=pdf

Pawl, K. (2018). Effective education: Online course design for adult learners. Lutheran Education, 74-76. https://files.eric.ed.gov/fulltext/EJ1244981.pdf

Richardson, J. C., Koehler, A. A., Besser, E. D., Caskurlu, S., Lim, J., \& Mueller, C. M. (2015). Conceptualizing and investigating instructor presence in online learning environments. International Review of Research in Open and Distributed Learning, 16, 256-297. https://doi.org/10.19173/irrodl.v16i3.2123

Shabiralyani, G., Hasan, K. S., Hamad, N., \& Iqbal, N. (2015). Impact of visual aids in enhancing the learning process case research: District Dera Ghazi Khan. Journal of Education and Practice, 6, 226-233.

https://files.eric.ed.gov/fulltext/EJ1079541.pdf

Steele, J., Nordin, E., Larson, E., \& McIntosh, D. (2017). Multiple access points within the online classroom: Where students look for information. The Turkish Online Journal of Distance Education, 18, 182-195. http://dergipark.gov.tr/tojde/issue/27160/285815

Steele, J. P., Robertson, S. N., \& Mandernach, B. J. (2017). Fostering first year students' perceptions of teacher presence in the online classroom via video lectures. Journal of the First-Year Experience $\mathcal{E}$ Students in Transition, 29, 79-92. https://eric.ed.gov/?id=EJ1161343

Steele, J., Robertson, S. N., \& Mandernach, B. J. (2018). Beyond content: The value of instructor-student connections in the online classroom. Journal of Scholarship of Teaching and Learning, 18, 130-150.

https://doi.org/10.14434/josotl.v18i4.23430

Sun, A., \& Chen. X. (2016). Online education and its effective practice: A research review. Journal of Information Technology Education: Research, 15, 157-190. https://doi.org/10.28945/3502

Thompson, P., Vogler, J. S., \& Ying, X. (2017). Strategic tooling: Technology for constructing a community of inquiry. Journal of Educators Online, 14, 117-124. https://files.eric.ed.gov/fulltext/EJ1150675.pdf

U.S. Department of Education, Recognition and Accreditation. (2019). The database of postsecondary institutions and programs. DAPIP.

https://ope.ed.gov/dapip/\#/home 


\section{Appendices}

\section{Appendix A}

\section{Matrix Example}

\section{Table 1}

\begin{tabular}{|c|c|c|c|c|c|c|c|c|c|}
\hline \multirow{2}{*}{$\begin{array}{l}\text { Instructional } \\
\text { Resource } \\
\text { (dimensions } \\
\text { of tool) }\end{array}$} & \multicolumn{9}{|c|}{ Indicators of Value or Importance } \\
\hline & $\begin{array}{l}\text { Provides } \\
\text { Immediate } \\
\text { Feedback }\end{array}$ & $\begin{array}{l}\text { Provides } \\
\text { value to } \\
\text { me (I like } \\
\text { it) }\end{array}$ & $\begin{array}{l}\text { Makes me } \\
\text { feel } \\
\text { connected } \\
\text { to the } \\
\text { instructor }\end{array}$ & $\begin{array}{l}\text { Makes me } \\
\text { feel } \\
\text { connected } \\
\text { to the } \\
\text { content }\end{array}$ & $\begin{array}{l}\text { Makes me } \\
\text { feel } \\
\text { connected } \\
\text { to my } \\
\text { classmates }\end{array}$ & $\begin{array}{l}\text { Makes } \\
\text { learning } \\
\text { easier for } \\
\text { me }\end{array}$ & $\begin{array}{l}\text { I have } \\
\text { access to } \\
\text { it at any } \\
\text { time }\end{array}$ & $\begin{array}{l}\text { It is what } \\
\text { I am used } \\
\text { to }\end{array}$ & $\begin{array}{l}\text { It is easy to } \\
\text { print out and } \\
\text { have on } \\
\text { hand if } \\
\text { needed }\end{array}$ \\
\hline & $\begin{array}{l}\text { This resource } \\
\text { provides } \\
\text { immediate } \\
\text { feedback to } \\
\text { foster my } \\
\text { understanding. }\end{array}$ & $\begin{array}{l}\text { I like } \\
\text { utilizing } \\
\text { this type } \\
\text { of } \\
\text { resource } \\
\text { to } \\
\text { support } \\
\text { my } \\
\text { learning. }\end{array}$ & $\begin{array}{l}\text { This } \\
\text { resource } \\
\text { helps me } \\
\text { feel more } \\
\text { connected } \\
\text { to my } \\
\text { instructor. }\end{array}$ & $\begin{array}{l}\text { This } \\
\text { resource } \\
\text { helps make } \\
\text { course } \\
\text { content } \\
\text { more } \\
\text { interesting. }\end{array}$ & $\begin{array}{l}\text { This } \\
\text { resource } \\
\text { helps me } \\
\text { connect } \\
\text { with my } \\
\text { classmates. }\end{array}$ & $\begin{array}{l}\text { This } \\
\text { resource } \\
\text { makes it } \\
\text { easier for } \\
\text { me to } \\
\text { understand } \\
\text { course } \\
\text { material. }\end{array}$ & $\begin{array}{l}\text { I like this } \\
\text { type of } \\
\text { resource } \\
\text { because I } \\
\text { have } \\
\text { access to } \\
\text { it when I } \\
\text { need it. }\end{array}$ & $\begin{array}{l}\text { I like this } \\
\text { resource } \\
\text { because it } \\
\text { aligns } \\
\text { with how } \\
\text { I am used } \\
\text { to } \\
\text { learning. }\end{array}$ & $\begin{array}{l}\text { I like this } \\
\text { resource } \\
\text { t because it is } \\
\text { important } \\
\text { for me to be } \\
\text { able to print } \\
\text { out } \\
\text { instructional } \\
\text { material. }\end{array}$ \\
\hline \multicolumn{10}{|l|}{$\begin{array}{l}\text { Visual static } \\
\text { (Pictures, } \\
\text { diagrams) }\end{array}$} \\
\hline \multicolumn{10}{|l|}{$\begin{array}{l}\text { Static general } \\
\text { (Text } \\
\text { direction) }\end{array}$} \\
\hline \multicolumn{10}{|l|}{$\begin{array}{l}\text { Text only } \\
\text { (Regular } \\
\text { Additional } \\
\text { Posts) }\end{array}$} \\
\hline \multicolumn{10}{|l|}{$\begin{array}{l}\text { Text only } \\
\text { (personal } \\
\text { responses } \\
\text { from } \\
\text { instructor } \\
\text { within the } \\
\text { individual } \\
\text { forum) }\end{array}$} \\
\hline \multicolumn{10}{|l|}{$\begin{array}{l}\text { Interactive } \\
\text { audio (Phone } \\
\text { call) }\end{array}$} \\
\hline \multicolumn{10}{|l|}{$\begin{array}{l}\text { Audio } \\
\text { (Instructor } \\
\text { audio } \\
\text { feedback) }\end{array}$} \\
\hline Audio & & & & & & & & & \\
\hline
\end{tabular}




\section{Appendix B}

Value of Personalization Survey (Part 1)

\section{Demographics}

* 1. Please create a special code word for yourself that you can remember. Type it below. Save this code as this will be your way of identifying yourself in future surveys within the course. Example: Skittles23

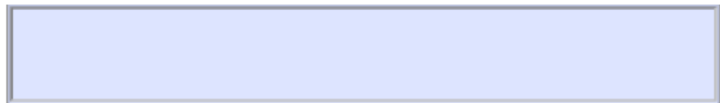

$\star 2$. What is your age?

*3. What year were you born?

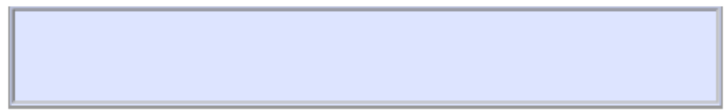

* 4. Please specify your ethnicity.

White

Hispanic or Latino

Black or African American

Native American or American Indian

Asian / Pacific Islander

Other

$\star 5$. What is your marital status?

Single, never married

Married or domestic partnership

Widowed

Divorced

Separated 
* 6 . What is your current employment status? Please select all that apply.

Employed for wages

Self-employed

Out of work and looking for work

Out of work but not currently looking for work

$\square$ A homemaker

$\square$ A student

$\square$ Military

Retired

Unable to work 
Instructor personalization dimension 1: Static Visuals

The following questions ask you about your instructor's use of static visuals in the online classroom. Static visuals refer to things such as diagrams or pictures. These may include diagrams, images, educational cartoons, photographs and graphics that the instructor adds to the resources, announcements, discussion or feedback areas of the course. Static just means there are no moving or live parts to the image.

* 7. Static visuals such as diagrams or pictures of my instructor within the classroom help me feel more connected to my instructor.

Strongly disagree $\quad$ Disagree

* 8. Static visuals such as diagrams or pictures the instructor incorporate into the classroom help me feel more connected to my instructor.

Strongly disagree Disagree neutral Agree N/A

* 9. I like utilizing static visuals such as diagrams or pictures the instructor incorporates into the classroom to support my learning.

Strongly disagree Disagree neutral Agree N/A

* 10 . Static visuals such as diagrams or pictures the instructor incorporate into the classroom help make course content more interesting

Strongly disagree Disagree neutral Agree N/A

* 11. Static visuals such as diagrams or pictures the instructor incorporates into the classroom help me connect with my classmates.

Strongly disagree Disagree neutral Agree N/A

* 12. Static visuals such as diagrams or pictures the instructor incorporate into the classroom make it easier for me to understand course material.

Strongly disagree Disagree Neutral Agree Ntrongly agree


* 13. I like static visuals such as diagrams or pictures the instructor incorporates into the classroom because I have access to it when I need it.

Strongly disagree Disagree neutral Agree Strongly agree N/A

* 14. I like static visuals such as diagrams or pictures the instructor incorporates into the classroom because it aligns with how I am used to learning.

Strongly disagree Disagree neutral

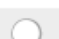

Agree

Strongly agree
N/A

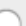

* 15 . I like static visuals such as diagrams or pictures the instructor incorporates into the classroom because it is important for me to be able to print out instructional material.

Strongly disagree

Disagree

neutral

Agree

Strongly agree

N/A
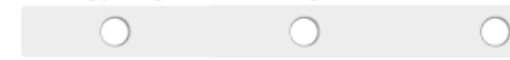
Dimension 2: Text

The following questions ask you about your instructor's use of written text in the online classroom.

Text refers to typed out directions, lectures, feedback, personal responses and more that the instructor adds to the resources, announcements, discussion or feedback areas of the course.

*1. Please enter the identification code previously created in the course.

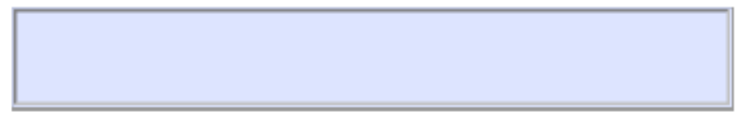

* 2 . When the instructor creates written direction clarifications in class it provides me immediate feedback to foster my understanding.

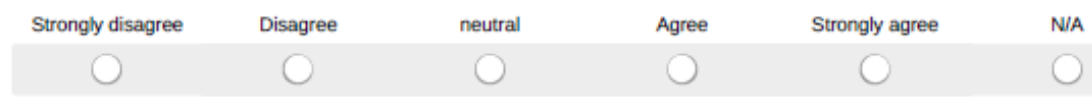

* 3 . Additional written posts that an instructor creates and incorporates into the discussion forum (such as added forum participation options) provide immediate feedback to foster my understanding.

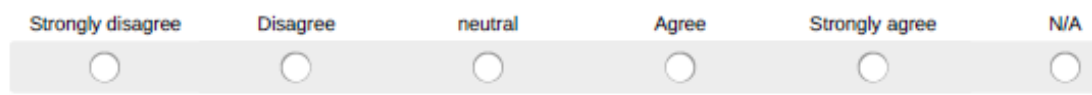

* 4. Personal written messages from an instructor (examples: embedded feedback on an assignment and personal replies within the individual forum) provides me with immediate feedback to foster my understanding.

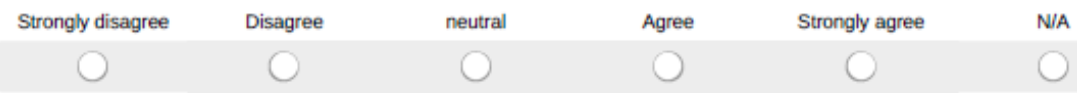

* 5.1 like to use written direction clarifications created by my instructor to support my learning.

\begin{tabular}{|c|c|c|c|c|c|}
\hline Strongly disagree & Disagree & neutral & Agree & Strongly agree & N/A \\
\hline
\end{tabular}

* 6.1 like to utilize additional written posts that an instructor creates and incorporates into the discussion forum (such as added forum participation options) to support my learning.

Strongly disagree $\quad$ Disagree $\quad$ neutral $\quad$ Agree $\quad$ Strongly agree N/A


* 7.1 like to utilize personal written messages from an instructor (examples: embedded feedback on an assignment and personal replies within the individual forum) to support my learning.

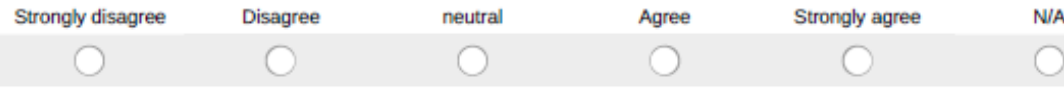

* 8 . When the instructor creates written direction clarifications in class, it helps me feel more connected to my instructor.

\begin{tabular}{cccccc} 
Strongly disagree & Disagree & neutral & Agree & Strongly agree & N/A \\
\hline & $\bigcirc$ & 0 & 0 & $O$ &
\end{tabular}

* 9. Additional written posts that an instructor creates and incorporates into the discussion forum (such as added forum participation options) help me feel more connected to my instructor.

Strongly disagree

Disagree

neutral

Agree

Strongly agree

N/A

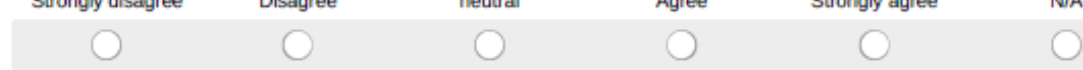

* 10. Personally written messages from an instructor (examples: embedded feedback on an assignment and personal replies within the individual forum) help me feel more connected to my instructor.

Strongly disagree Disagree neutral

Agree

Strongly agree

N/A

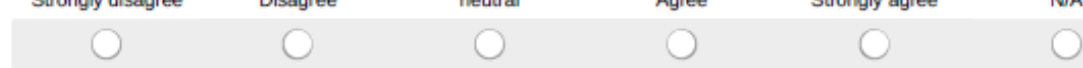

* 11. When the instructor creates written direction clarifications in class, it helps make course content more interesting.

Strongly disagree

Disagree

neutral

Agree

Strongly agree

N/A

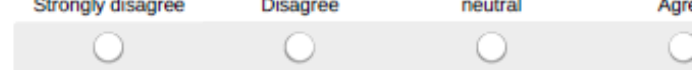

* 12. Additional written posts that an instructor creates and incorporates into the discussion forum (such as added forum participation options) help make course content more interesting.

Strongly disagree

Disagree

neutral

Agree

Strongly agree

N/A
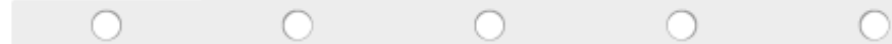

* 13. Personally written messages from an instructor (examples: embedded feedback on an assignment and personal replies within the individual forum) help to make course content more interesting.

Strongly disagree

Disagree

neutral

Agree

Strongly agree

N/A

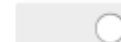

* 14. Additional written posts that an instructor creates and incorporates into the discussion forum (such as added forum participation options) help me connect with my classmates.

Strongly disagree

Disagree

neutral

Agree

Strongly agree

N/A 
* 15. Personal written messages from an instructor (examples: embedded feedback on an assignment and personal replies within the individual forum) help me connect with my classmates.

Strongly disagree $\quad$ Disagree $\quad$ neutral $\quad$ Agree $\quad$ Strongly agree $\quad$ N/A

* 16 . When the instructor creates written direction clarifications in class, it makes it easier for me to understand course material.

\begin{tabular}{|c|c|c|c|c|c|}
\hline Strongly disagree & Disagree & neutral & Agree & Strongly agree & N/A \\
\hline
\end{tabular}

* 17. Additional written posts that an instructor creates and incorporates into the discussion forum (such as added forum participation options) make it easier for me to understand course material.

\begin{tabular}{|c|c|c|c|c|}
\hline Strongly disagree & Disagree & neutral & Agree & Strongly agree \\
\hline
\end{tabular}

* 18. Personally written messages from an instructor (examples: embedded feedback on an assignment and personal replies within the individual forum) make it easier for me to understand course material.

Strongly disagree

Disagree

neutral

Agree

Strongly agree

N/A

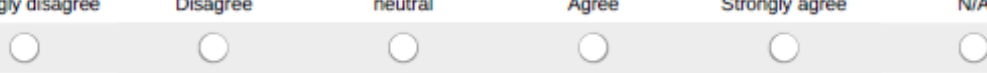

* 19. I like when the instructor creates written direction clarifications in class because I have access to it when I need it.

Strongly disagree

Disagree

neutral

Agree

Strongly agree

N/A

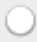

$\bigcirc$
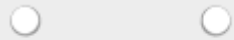

20. I like additional written posts that an instructor creates and incorporates into the discussion forum (such as added forum participation options) because I have access to it when I need it.

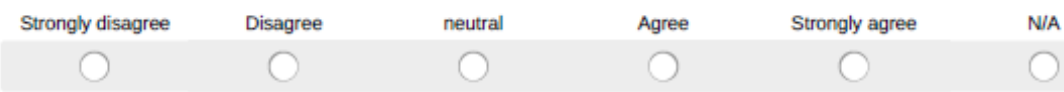

21. I like personally written messages from an instructor (examples: embedded feedback on an assignment and personal replies within the individual forum) because I have access to it when I need it.

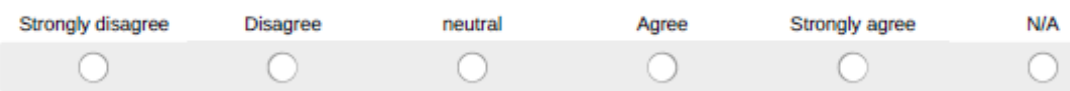

22. I like when the instructor creates written direction clarifications in class because it is important for me to be able to print out instructional material.

Strongly disagree Disagree neutral Agree Strongly agree N/A 
23. I like additional written posts that an instructor creates and incorporates into the discussion forum (such as added forum participation options) because it is important for me to be able to print out instructional material.

Strongly disagree Disagree neutral Agree Strongly agree N/A

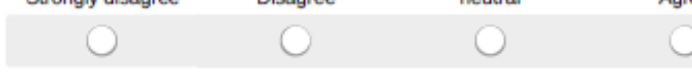

24. I like personally written messages from an instructor (examples: embedded feedback on an assignment and personal replies within the individual forum) because it is important for me to be able to print out instructional material.

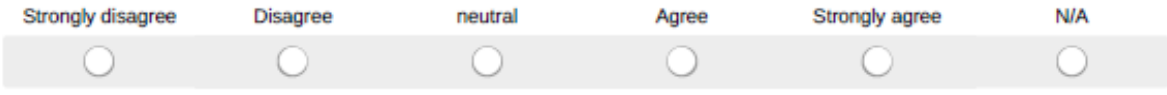

25. I like when the instructor creates written direction clarifications in class because it aligns with how I am used to learning.

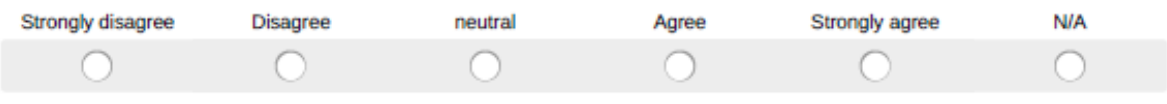

26. I like additional written posts that an instructor creates and incorporates into the discussion forum (such as added forum participation options) because it aligns with how I am used to learning.

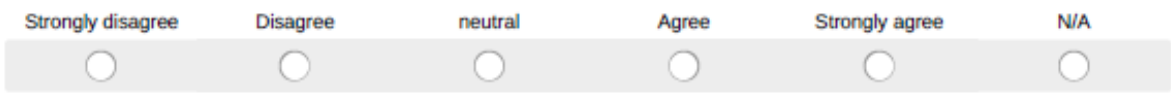

27. I like personally written messages from an instructor (examples: embedded feedback on an assignment and personal replies within the individual forum) because it aligns with how I am used to learning.

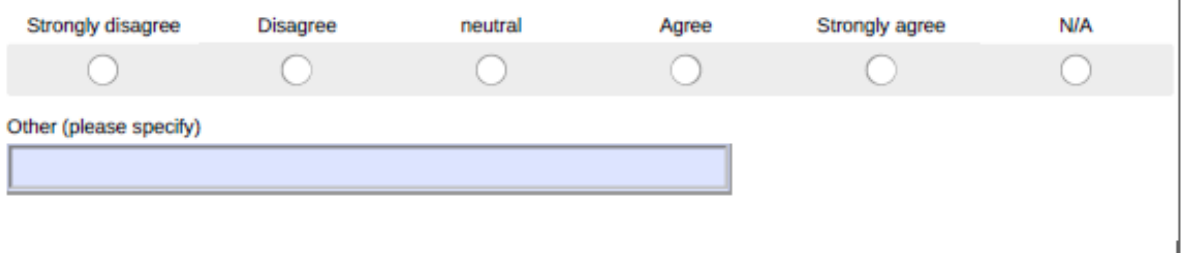


Dimension 3: Audio

The following questions ask you about your instructor's use of audio in the online classroom. Audio refers to phone calls, audio lectures, voice-recorded feedback, podcasts and more that the instructor adds to the resources, announcements, discussion or feedback areas of the course. GCU created learning material includes things like the module lectures, extra readings and course materials.

* 1 . Please enter the identification code previously created in the course.

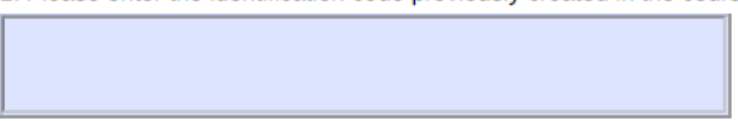

* 2. Audio feedback on assignments from my instructor provide immediate feedback to foster my understanding.

Strongly disagree $\quad$ Disagree $\quad$ neutral $\quad$ Strongly agree

* 3. Audio lectures with an instructor's voice provide immediate feedback to foster my understanding.

Strongly disagree

Disagree neutral

Agree

Strongly agree

* 4. GCU created learning material (such as the module lectures, extra readings, and other course materials) in audio format provide immediate feedback to foster my understanding.

Strongly disagree

Disagree

neutral

Agree

Strongly agree

N/A

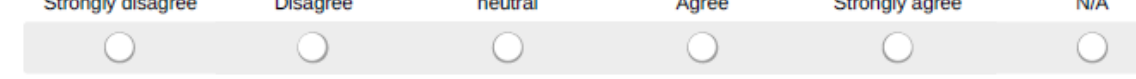

* 5 . I like utilizing phone calls with an instructor to support my learning.

Strongly disagree

Disagree

neutral

Agree

Strongly agree

N/A

*6. I like utilizing audio feedback on assignments from my instructor to support my learning.

Strongly disagree

Disagree

neutral

Agree

Strongly agree

N/A 
* 7 . I like utilizing audio lectures with an instructor's voice to support my learning.

Strongly disagree

Disagree

neutral

Agree

Strongly agree

N/A

Other (please specify)

* 8 . I like utilizing GCU created learning material in audio format to support my learning.

Strongly disagree Disagree neutral

Agree

Strongly agree<smiles>C=CO</smiles>

* 9. Phone calls with an instructor help me feel more connected to my instructor.

Strongly disagree

Disagree

neutral

Agree

Strongly agree

N/A
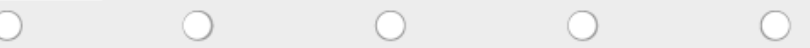

* 10. Audio feedback on assignments from my instructor helps me feel more connected to my instructor.

Strongly disagree

Disagree

neutral

Agree

Strongly agree

N/A
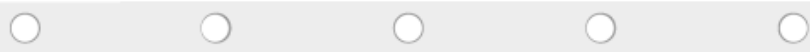

* 11. Audio lectures with an instructor's voice help me feel more connected to my instructor.

Strongly disagre

Disagree

neutral

Agree

Strongly agree

N/A

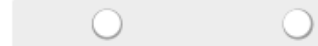

* 12. GCU created learning material in audio format helps me feel more connected to my instructor.

Strongly disagree

Disagree

neutral

Agree

Strongly agree

N/A
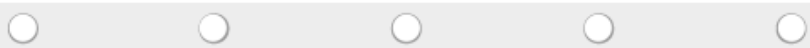

* 13. Phone calls with an instructor help make course content more interesting.

Strongly disagree

Disagree

neutral

Agree

Strongly agree

N/A
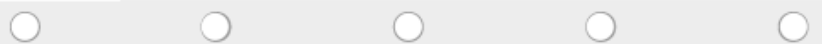

* 14. Audio feedback on assignments from my instructor helps make course content more interesting.

Strongly disagree

Disagree

neutral

Agree

Strongly agree

N/A
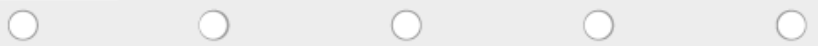

* 15. Audio lectures with an instructor's voice help make course content more interesting.

Strongly disagree

Disagree

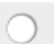

neutral

Agree

Strongly agree

N/A 
* 16. GCU created learning material in audio format helps make course content more interesting.

Strongly disagree

Disagree

neutral

Agree

Strongly agree
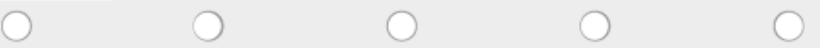

* 17. Phone calls with an instructor make it easier for me to understand course material.

Strongly disagree

Disagree

neutral

Agree

Strongly agree

N/A

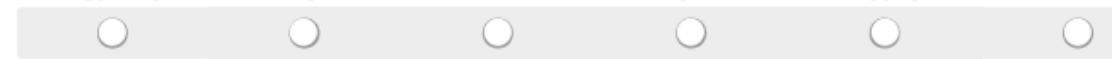

* 18. Audio feedback on assignments from my instructor makes it easier for me to understand course material.

Strongly disagree Disagree neutral Agree Strongly agree N/A
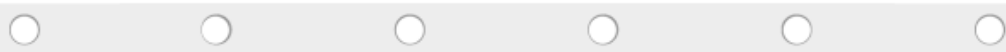

19. Audio lectures with an instructor's voice make it easier for me to understand course material.

Strongly disagree Disagree

20. GCU created learning material in audio format makes it easier for me to understand course material.

Strongly disagree Disagree

21. I like audio feedback on assignments from my instructor because I have access to it when I need it.

Strongly disagree Disagree

22. I like audio lectures with an instructor's voice because I have access to it when I need it.

Strongly disagree $\quad$ Disagree

23. I like GCU created learning material in audio format because I have access to it when I need it.

\begin{tabular}{|c|c|c|c|c|}
\hline Strongly disagree & Disagree & neutral & Agree & Strongly agree \\
\hline
\end{tabular}

24. I like phone calls with an instructor because it aligns with how I am used to learning.

Strongly disagree

Disagree

neutral

Strongly agree

N/A

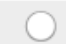

N/A

)


25. I like audio feedback on assignments from my instructor because it aligns with how I am used to learning.

Strongly disagree

Disagree

neutral

Agree

Strongly agree

N/A

26. I like audio lectures with an instructor's voice because it aligns with how I am used to learning.

Strongly disagree

Disagree

neutral

Agree

Strongly agree

N/A
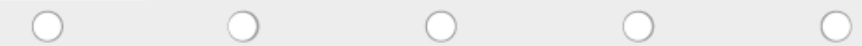

* 27. Phone calls with an instructor provides immediate feedback to foster my understanding.

Strongly disagree Disagree neutral Agree N/A

* 28 . Were there any phrases or questions that were unclear? If so, what question(s) were unclear and why? 


\section{Value of Personalization Survey (Part 4)}

Instructor personalization dimension 4: Video

The following questions ask you about your instructor's use of videos in the online classroom. Videos refer to either live or record video lectures, feedback, announcements, and more that the instructor adds to the resources, announcements, discussion or feedback areas of the course.

* 1 . Please enter the identification code previously created in the course.

* 2. Live video conferences with myself and an instructor provide immediate feedback to foster my understanding.

Strongly disagree Disagree neutral $\quad$ Agree N/A

Other (please specify)

* 3. Live video conferences with my classmates \& instructor provide immediate feedback to foster my understanding.

Strongly disagree

Disagree

neutral

Agree

Strongly agree

N/A

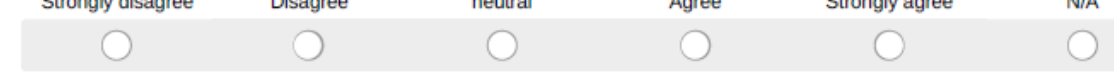

* 4. Video lectures an instructor has made provide immediate feedback to foster my understanding.

Strongly disagree

Disagree

neutral

Agree

Strongly agree

N/A

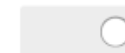

* 5 . Video feedback an instructor has made provides immediate feedback to foster my understanding.

Strongly disagree $\quad$ Disagree $\quad$ neutral $\quad$ Agree $\quad$ Strongly agree

* 6. Content videos the instructor has made but is not visible in provides immediate feedback to foster my understanding.

Strongly disagree

Disagree

neutral

Agree

Strongly agree

N/A 
* 7. I like live video conferences with myself and my instructor to support my learning. (An example would be Zoom).

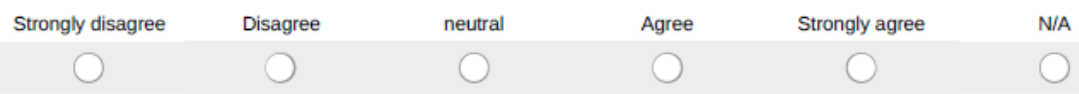

* 8. I like live video conference with my classmates and instructor to support my learning.

Strongly disagree $\quad$ Disagree $\quad$ neutral $\quad$ Agree Ntrongly agree

* 9 . I like video lectures an instructor has made to support my learning.

Strongly disagree $\quad$ Disagree $\quad$ neutral $\quad$ Agree $\quad$ Strongly agree

* 10. I like video feedback an instructor has made to support my learning.

Strongly disagree $\quad$ Disagree $\quad$ neutral $\quad$ Agree $\quad$ Strongly agree N/A

Other (please specify)

* 11. I like content videos the instructor has made but is not visible in to support my learning.

Strongly disagree Disagree neutral

Agree Strongly agree N/A $\bigcirc \quad \bigcirc \quad \bigcirc$

* 12. Live video conferences with myself and an instructor help me feel more connected to my instructor.
Strongly disagree
Disagree
neutral
Agree
Strongly agree
N/A

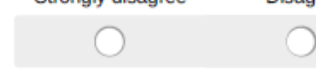
Other (please specity)

* 13. Live video conferences with my classmates and instructor help me feel more connected to my instructor.

Strongly disagree $\quad$ Disagree $\quad$ neutral $\quad$ Strongly agree

* 14. Video lectures an instructor has made help me feel more connected to my instructor.

Strongly disagree Disagree $\quad$ Agree $\quad$ Strongly agree N/A


* 15. Video feedback an instructor has made help me feel more connected to my instructor.

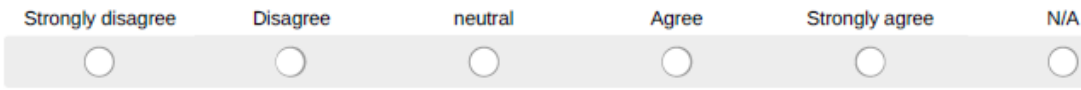

Other (please specify)

* 16. Content videos the instructor has made but is not visible in help me feel more connected to my instructor.

Strongly disagree

Disagree

neutral

Agree

Strongly agree

N/A
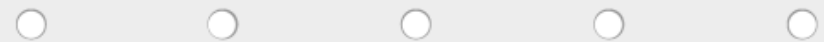

* 17. Live video conferences with myself and an instructor help make course content more interesting.

Strongly disagree

Disagree
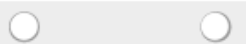

neutral

Agree

Strongly agree

N/A

* 18. Live video conferences with my classmates and instructor help make course content more interesting.

Strongly disagree

Disagree

neutral

Agree

Strongly agree

N/A
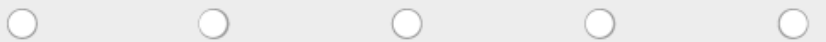

* 19. Video lectures an instructor has made help make course content more interesting.

\begin{tabular}{l} 
Strongly disagree Disagree $\quad$ neutral \\
Other (please specify) \\
\hline
\end{tabular}

20. Video feedback an instructor has made help make course content more interesting.

\begin{tabular}{|c|c|c|c|c|c|}
\hline Strongly disagree & Disagree & neutral & Agree & Strongly agree & N/A \\
\hline
\end{tabular}

21. Content videos the instructor has made but is not visible in help make course content more interesting. Strongly disagree Disagree neutral Agree Strongly agree N/A
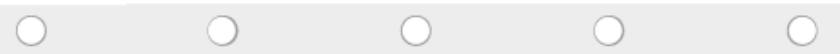

22. Live video conferences with my classmates and instructor help me connect with my classmates.

Strongly disagree

Disagree

neutral

Strongly agree

N/A 
23. Live video conferences with myself and an instructor make it easier for me to understand course material.

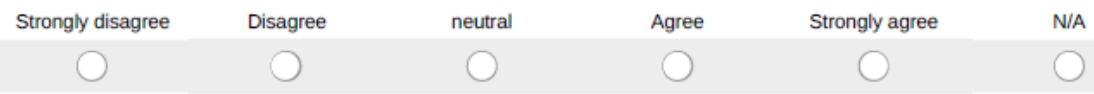

24. Video lectures an instructor has made make it easier for me to understand course material.

Strongly disagree Disagree $\quad$ Agree $\quad$ Strongly agree N/A

25. Video feedback an instructor has made make it easier for me to understand course material.

Strongly disagree Disagree $\quad$ Agree $\quad$ Strongly agree

26. Content videos the instructor has made but is not visible in make it easier for me to understand course material.

Strongly disagree Disagree neutral Agree N/A

27. I like video lectures an instructor has made because I have access to it when I need it.

$\begin{array}{llll}\text { Strongly disagree Disagree } & \text { Agree } & \text { Strongly agree } \\ \text { Other (please specify) } & & \end{array}$

28. I like video feedback an instructor has made because I have access to it when I need it.

Strongly disagree Disagree $\quad$ neutral $\quad$ Agree N/A

29. I like content videos the instructor has made but is not visible in because I have access to it when I need it.

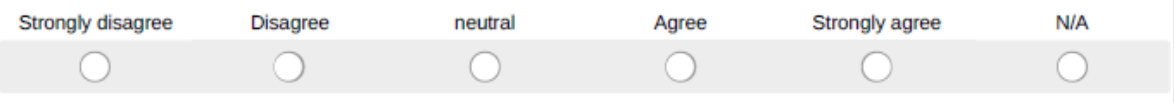

30. I like live video conferences with myself and an instructor because it aligns with how I am used to learning.

Strongly disagree Disagree $\quad$ Agree $\quad$ Strongly agree


23. Live video conferences with myself and an instructor make it easier for me to understand course material.

Strongly disagree

Disagree

neutral

Agree

Strongly agree

N/A

24. Video lectures an instructor has made make it easier for me to understand course material.

Strongly disagree

Disagree

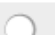

neutral

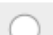

Agree

Strongly agree

N/A

25. Video feedback an instructor has made make it easier for me to understand course material.
Disagree

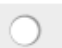

neutral

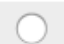

Agree

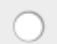

N/A

26. Content videos the instructor has made but is not visible in make it easier for me to understand course material.

Strongly disagree

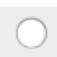

Disagree

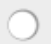

neutral

(

Agree

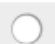

Strongly agree

N/A

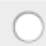

27. I like video lectures an instructor has made because I have access to it when I need it.

Strongly disagree $\quad$ Disagree $\quad$ neutral $\quad$ Agree $\quad$ Strongly agree N/A

Other (please specify)

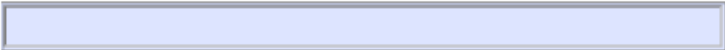

28. I like video feedback an instructor has made because I have access to it when I need it.

Strongly disagree

Disagree

neutral

Agree

Strongly agree

N/A
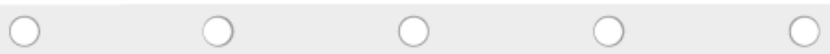

29. I like content videos the instructor has made but is not visible in because I have access to it when I need it.

Strongly disagree

Disagree

neutral

Agree

Strongly agree

N/A
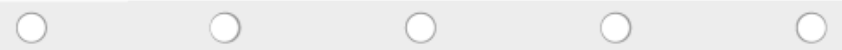

30. I like live video conferences with myself and an instructor because it aligns with how I am used to learning.

Strongly disagree

Disagree

neutral

Agree

Strongly agree

N/A
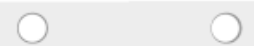

(1)
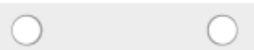
31. I like live video conference with my classmates and instructor because it aligns with how I am used to learning.

Strongly disagree

32. I like video lectures an instructor has made because it aligns with how I am used to learning.

Strongly disagree Disagree neutral Agree Strongly agree

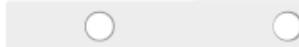

33. I like video feedback an instructor has made because it aligns with how I am used to learning

Strongly disagree Disagree Neutral $\quad$ Agree

34. I like content videos the instructor has created even if they are not seen video because it aligns with how I am used to learning.

Strongly disagree $\quad$ Disagree $\quad$ neutral $\quad$ Strongly agree N/A




\section{Appendix C}

\section{Means per Communication Medium Sub-Sections and Perceived Value}

Means provided below are the mean Likert-score across all participants per survey question. An X represents a survey question that was thrown out during the survey creation stage.

\section{Table 2}

\begin{tabular}{|c|c|c|c|c|c|c|c|c|c|}
\hline \multirow{3}{*}{$\begin{array}{l}\text { Communication } \\
\text { Medium } \\
\text { (Example of } \\
\text { instructional } \\
\text { resource) }\end{array}$} & \multicolumn{9}{|c|}{ Indicators of Value or Importance - Means } \\
\hline & $\begin{array}{l}\text { Provides } \\
\text { Immediate } \\
\text { Feedback }\end{array}$ & $\begin{array}{l}\text { Provides } \\
\text { value to } \\
\text { me } \\
\text { (I like it) }\end{array}$ & $\begin{array}{l}\text { Makes me } \\
\text { feel } \\
\text { connected } \\
\text { to the } \\
\text { instructor }\end{array}$ & $\begin{array}{l}\text { Makes me } \\
\text { feel } \\
\text { connected to } \\
\text { the content }\end{array}$ & $\begin{array}{l}\text { Makes me } \\
\text { feel } \\
\text { connected to } \\
\text { my } \\
\text { classmates }\end{array}$ & $\begin{array}{l}\text { Makes } \\
\text { learning } \\
\text { easier for me }\end{array}$ & $\begin{array}{l}\text { I have } \\
\text { access to } \\
\text { it at any } \\
\text { time }\end{array}$ & $\begin{array}{l}\text { It is what } \\
\text { I am used } \\
\text { to }\end{array}$ & $\begin{array}{l}\text { It is easy to } \\
\text { print out and } \\
\text { have on hand } \\
\text { if needed }\end{array}$ \\
\hline & $\begin{array}{l}\text { This resource } \\
\text { provides } \\
\text { immediate } \\
\text { feedback to } \\
\text { foster my } \\
\text { understanding. }\end{array}$ & $\begin{array}{l}\text { I like } \\
\text { utilizing } \\
\text { this type } \\
\text { of } \\
\text { resource } \\
\text { to support } \\
\text { my } \\
\text { learning. }\end{array}$ & $\begin{array}{l}\text { This } \\
\text { resource } \\
\text { helps me } \\
\text { feel more } \\
\text { connected } \\
\text { to my } \\
\text { instructor. }\end{array}$ & $\begin{array}{l}\text { This } \\
\text { resource } \\
\text { helps make } \\
\text { course } \\
\text { content } \\
\text { more } \\
\text { interesting. }\end{array}$ & $\begin{array}{l}\text { This } \\
\text { resource } \\
\text { helps me } \\
\text { connect } \\
\text { with my } \\
\text { classmates. }\end{array}$ & $\begin{array}{l}\text { This } \\
\text { resource } \\
\text { makes it } \\
\text { easier for me } \\
\text { to } \\
\text { understand } \\
\text { course } \\
\text { material. }\end{array}$ & $\begin{array}{l}\text { I like this } \\
\text { type of } \\
\text { resource } \\
\text { because I } \\
\text { have } \\
\text { access to } \\
\text { it when I } \\
\text { need it. }\end{array}$ & $\begin{array}{l}\text { I like this } \\
\text { resource } \\
\text { because it } \\
\text { aligns } \\
\text { with how } \\
\text { I am used } \\
\text { to } \\
\text { learning. }\end{array}$ & $\begin{array}{l}\text { I like this } \\
\text { resource } \\
\text { because it is } \\
\text { important for } \\
\text { me to be able } \\
\text { to print out } \\
\text { instructional } \\
\text { material. }\end{array}$ \\
\hline
\end{tabular}

\begin{tabular}{|c|c|c|c|c|c|c|c|c|c|}
\hline $\begin{array}{l}\text { Visual static } \\
\text { (Pictures, } \\
\text { diagrams) }\end{array}$ & $X$ & 4.31 & 4.21 & 4.41 & 3.86 & 4.40 & 4.37 & 4.15 & 4.14 \\
\hline $\begin{array}{l}\text { Static general } \\
\text { (Text directions) }\end{array}$ & 4.50 & 4.50 & 4.36 & 4.39 & $x$ & 4.50 & 4.59 & 4.25 & 4.02 \\
\hline $\begin{array}{l}\text { Text only } \\
\text { (Regular } \\
\text { Additional Posts) }\end{array}$ & 4.48 & 4.49 & 4.37 & 4.45 & 4.26 & 4.44 & 4.54 & 4.25 & 4.00 \\
\hline
\end{tabular}

Text only

(personal

$\begin{array}{llllllllll}\text { responses from } & 4.61 & 4.58 & 4.52 & 4.44 & 3.95 & 4.47 & 4.52 & X & 3.94 \\ \text { instructor within } & 4.94 & \end{array}$

the individual

forum)

\begin{tabular}{|c|c|c|c|c|c|c|c|c|c|}
\hline $\begin{array}{l}\text { Interactive audio } \\
\text { (Phone call) }\end{array}$ & $X$ & 3.43 & 3.63 & 3.33 & $x$ & 3.50 & $x$ & 3.24 & $x$ \\
\hline $\begin{array}{l}\text { Audio } \\
\text { (Instructor audio } \\
\text { feedback) }\end{array}$ & 3.97 & 3.91 & 3.86 & 3.80 & $x$ & 3.82 & 3.91 & 3.62 & $X$ \\
\hline $\begin{array}{l}\text { Audio } \\
\text { (Instructor audio } \\
\text { lecture) }\end{array}$ & 4.09 & 4.07 & 3.98 & 3.93 & $X$ & 4.00 & 4.01 & 3.79 & $X$ \\
\hline $\begin{array}{l}\text { Generic non- } \\
\text { synchronous } \\
\text { audio } \\
\text { (Lecture without } \\
\text { your instructor's } \\
\text { voice) }\end{array}$ & 4.18 & 3.89 & 3.98 & 3.93 & $x$ & 3.89 & 4.04 & $x$ & $X$ \\
\hline
\end{tabular}




\begin{tabular}{|c|c|c|c|c|c|c|c|c|c|}
\hline $\begin{array}{l}\text { Communication } \\
\text { Medium }\end{array}$ & & $\mathrm{s}$ of $\mathrm{Va}$ & or $\operatorname{Im}_{1}$ & $c e-M$ & & & & & \\
\hline $\begin{array}{l}\text { Interactive } \\
\text { synchronous } \\
\text { video with } \\
\text { instructor } \\
\text { (Zoom call) }\end{array}$ & 3.71 & 3.53 & 3.62 & 3.55 & $X$ & 3.56 & $x$ & 3.42 & $x$ \\
\hline $\begin{array}{l}\text { Interactive } \\
\text { synchronous } \\
\text { video with } \\
\text { instructor and } \\
\text { classmates } \\
\text { (Zoom call) }\end{array}$ & 3.48 & 3.48 & 3.51 & 3.55 & 3.52 & $x$ & $x$ & 3.32 & $x$ \\
\hline $\begin{array}{l}\text { Non- } \\
\text { synchronous } \\
\text { lecture video } \\
\text { with instructor }\end{array}$ & 4.05 & 4.10 & 3.99 & 4.07 & $x$ & 4.08 & 4.24 & 3.76 & $x$ \\
\hline $\begin{array}{l}\text { Non- } \\
\text { synchronous } \\
\text { video feedback } \\
\text { with instructor }\end{array}$ & 4.00 & 3.98 & 3.83 & 3.89 & $X$ & 3.95 & 4.07 & 3.71 & $x$ \\
\hline
\end{tabular}

John Steele is an Associate Professor at Grand Canyon University who teaches University Introduction, Education, and Psychology classes. He is also certified K-12 School Counselor, certified elementary teacher, with adjunct teaching experience at Phoenix Community College and GCU with 10 years of experience in higher education. He is a GCU alumnus and is currently pursuing his doctoral degree in General Psychology with an emphasis in Integrating Technology, Learning, and Psychology at GCU. John's professional interests include research in online learning and academic integrity.

Sarah Robertson is an online instructor who teaches full time at Grand Canyon University for the College of Humanities and Social Sciences. With more than 13 years of experience in education and a PhD in psychology, her professional pursuits include action research efforts to further improve student engagement, teaching presence, student and teacher motivation, and information retention/application within both online and traditional courses.

B. Jean Mandernach, PhD, is Executive Director of the Center for Innovation in Research and Teaching at Grand Canyon University. Her research focuses on enhancing student learning in the online classroom through innovative instructional and assessment strategies. She explores strategies for integrating efficient online instruction in a manner that maximizes student learning, satisfaction, and engagement. In addition, she has interests in the development of effective faculty evaluation models, perception of online degrees, data analytics, and faculty workload considerations. 